\title{
EN TORNO A LA INICIATIVA DE CORREDURÍA
}

\author{
Salvador VALENCIA CARMONA
}

\section{LA INICIATIVA Y SUS ARGUMENTOS}

La opinión que se vertirá en este documento, se refiere a la iniciativa presentada el 25 de noviembre de 2008 por el senador Federico Döring Casar, perteneciente al grupo parlamentario del Partido Acción Nacional, que propone reformar, derogar y adicionar diversas disposiciones de la Ley Federal de Correduría Pública.

Se plantea en la iniciativa un problema importante para el país, que suscita diversas inquietudes constitucionales y legales; obviamente reviste singular interés para los interesados en las reformas. Antes de examinar el documento de que se trata, precisa añadir que iniciativas similares a la que se comentará se han presentado con anterioridad, sin que llegasen a ser aprobadas. ${ }^{1}$

Los argumentos básicos que presenta la iniciativa son los siguientes: a) es menester otorgar fe pública más amplia a los corredores para reducir el costo de los servicios notariales; b) una economía dinámica y moderna requiere de una oferta creciente de prestadores de servicios de fedación, se aportan datos estadísticos proporcionados por el Colegio Nacional de Correduría Pública; c) con base en las facultades implícitas previstas en la fracción XXX del artículo 73, así como en los artículos 121 y 124, se proponen diversas reformas a la Ley de Correduría Pública

1 Véase la iniciativa presentada por la diputada Nora Yu Hernández en 2004. http://gaceta.diputados.gob.mx/Gaceta/59/2004/dic/20041214I.html\#Ini20041216IniYu. En el Senado se presentó una iniciativa similar, la cual es consultable en www.juridicas. unam.mx/publica/librev/rev/podium/.../pr26.pdf. 
Federal; d) si se aprueban las reformas mencionadas, los corredores públicos podrían actuar tanto en sus plazas asignadas como en las de cualquiera del territorio nacional, e intervenir como fedatarios en contratos, convenios, actos o hechos jurídicos, sean de naturaleza mercantil o civil.

\section{LA POLÉMICA GREMIAL}

La iniciativa en cuestión se inserta en lo que ahora puede denominarse una polémica gremial que desde hace varios años se libra entre los notarios y los corredores públicos, que versa esencialmente sobre su esferas de atribuciones en fe pública y particularmente en la prohibición que en materia inmobiliaria tiene el corredor.

Se han esgrimido diversas razones por el notariado contra una iniciativa como la que se discute:

1. Los actos y hechos jurídicos que se proponen realicen los corredores pertenecen al derecho civil, materia de carácter local en aplicación del principio del artículo 124 constitucional, así como lo dispuesto para el Distrito Federal en el artículo 122.

2. El uso de las facultades implícitas es incorrecto y vulnera al sistema federal, dado que la Constitución dispone en el artículo 121, fracción II, que los bienes muebles e inmuebles se rigen por la ley de su ubicación.

3. En diversas leyes federales, como en las propias interpretaciones de los legisladores, se han reconocido como locales la regulación de inmuebles, poderes y mandatos, además de la propia función notarial.

4. La interpretación del Poder Judicial federal ${ }^{2}$ ha señalado que los corredores públicos tienen facultades exclusivamente para intervenir en actos de materia mercantil, no de naturaleza civil.

5. El ordenamiento para regir a notarios y corredores debe ser una ley de carácter general, y no una de índole federal.

2 En un documentado estudio, el distinguido constitucionalista José Gamas Torruco hace mención de iniciativas anteriores presentadas. Por su parte, los colegios de notarios de Jalisco, Veracruz, Tamaulipas, Puebla y Tabasco, han emitido diversas comunicaciones a los diputados y senadores del Congreso de la Unión, al presidente de la República y al secretario de Economía, para hacerles notar sus objeciones constitucionales y legales a la Ley de Correduría federal y particularmente a las reformas que el propio gobierno federal y algunos legisladores han pretendido impulsar. 
Por su parte, la correduría pública ha venido pugnando por atribuciones más amplias tanto en materia de fe pública como inmobiliaria. ${ }^{3} \mathrm{Se}$ sostiene también que el principio establecido en el artículo 121 no es absoluto, tiene diversas excepciones y puede el Congreso Federal reglamentar dicho precepto a través de las facultades implícitas.

Mas aún, incluso con la legislación vigente, los corredores han sostenido:

1. Que cuando se trate de sociedad mercantiles con aportación de bienes inmuebles no debe haber prohibición para el corredor.

2. Si el acto jurídico mercantil es sobre bienes inmuebles, realizado entre personas morales mercantiles no existe prohibición para el corredor.

3. Si el acto jurídico es de los denominados mixtos, una parte es sociedad mercantil y otra no lo es tampoco debe haber prohibición.

4. Cuando se trata de créditos refaccionarios y otros similares, el corredor puede intervenir válidamente en operaciones inmobiliarias. ${ }^{4}$

\section{LOS INCONVENIENTES DE LA INICIATIVA}

En principio, desde la perspectiva del orden jurídico vigente, resulta que el Congreso de la Unión actuaría vulnerando principios constitucionales si estableciese normas, sin la reforma constitucional correspondiente que la haga concurrente, que afectase la materia civil que forma parte de la legislación local y que ha sido una de las potestades residuales del artículo 124. A este argumento principal, se pueden agregar el conflicto de normas federales y locales que al respecto surgirían; el uso posiblemente excesivo de las facultades implícitas; las contradicciones y antinomias que habría con disposiciones e interpretaciones legislativas federales; así como con las propias interpretaciones que ha ofrecido el propio Poder Judicial federal.

3 Véase Reséndiz Núñez, Cuauhtémoc et. al., La nueva correduría pública mexicana, México, ITAM, 1994; Camposeco Cadena, Miguel Ángel, Funciones de la correduría pública, edición del autor, 1998.

4 Cfr. Platero Fernández, Gonzalo y Villalobos, Víctor Hugo, "Las atribuciones coincidentes de corredores públicos y notarios”, en Reséndiz Núñez, Cuauhtémoc et. al., op. cit., nota anterior, pp. 141 y ss; Camposeco Cadena, Miguel Ángel, op. cit., nota anterior, pp. 3 y ss. 
Vale también decir que la iniciativa que se comenta confunde los términos de ley general y ley federal como son entendidos en el ámbito nacional. Si bien la expresión ley general es criticada porque toda ley en esencia es general, en el orden jurídico mexicano se ha denominado así a los ordenamientos que se refieren a las facultades concurrentes y que distribuyen funciones entre la federación, las entidades locales y los propios municipios, como serían las leyes generales en materia de salud y educativas. Este no es el caso de la Ley Federal de Correduría Pública, cuya propia denominación en sus ámbitos personal y material de validez se refieren exclusivamente a los corredores públicos, auxiliares del comercio, materia federal, de ahí que una ley federal no pueda tornarse por simple decisión del Congreso en ley general.

A este respecto, conviene recordar el criterio de la Suprema Corte acerca del concepto y alcances de lo que debe entenderse por ley general, en su tesis aislada ha dicho lo siguiente: ${ }^{5}$

La lectura del precepto citado permite advertir la intención del Constituyente de establecer un conjunto de disposiciones de observancia general que, en la medida en que se encuentren apegadas a lo dispuesto por la Constitución Política de los Estados Unidos Mexicanos, constituyan la "ley suprema de la Unión". En este sentido, debe entenderse que las leyes del Congreso de la Unión a las que se refiere el artículo constitucional no corresponden a las leyes federales, esto es, a aquellas que regulan las atribuciones conferidas a determinados órganos con el objeto de trascender únicamente al ámbito federal, sino que se trata de leyes generales que son aquellas que pueden incidir válidamente en todos los órdenes jurídicos parciales que integran al Estado mexicano. Es decir, las leyes generales corresponden a aquellas respecto a las cuales el Constituyente o el Poder Revisor de la Constitución ha renunciado expresamente a su potestad distribuidora de atribuciones entre las entidades políticas que integran el Estado mexicano, lo cual se traduce en una excepción al principio establecido por el artículo 124 constitucional. Además, estas leyes no son emitidas motu proprio por el Congreso de la Unión, sino que tienen su origen en cláusulas constitucionales que obligan a éste a dictarlas, de tal manera que una vez promulgadas y publicadas, deberán ser aplicadas por las autoridades federales, locales, del Distrito Federal y municipales.

5 Leyes Generales. Interpretación del artículo 133 constitucional, 2007, tesis P. VII, Semanario Judicial de la Federación y su gaceta XXV, abril de 2007, p. 5. 
Finalmente, habría que pensar si conviene en política legislativa llegar a la identificación y asimilación funcional de notarios y corredores, como en la práctica resultaría de las reformas propuestas, con ventajas evidentes para estos últimos. Más todavía, es menester reflexionar que los efectos de tales reformas no se advierten pacíficos, se presentarían múltiples controversias y acciones de inconstitucionalidad, debates acalorados y hasta encono entre los involucrados.

\section{MáS ALLÁ DE LA POLÉMICA Y LA INICIATIVA}

El problema necesita replantearse; la urgencia nacional es otra que la mera querella entre notarios y corredores. Como han demostrado numerosos estudios, el desarrollo y progreso de un país requiere de seguridad y certeza en su régimen de propiedad, para lograrlo es menester que el Estado brinde facilidades para consolidarlo y se cuente con notarios, corredores y profesionistas que hagan posible prestar los diversos servicios que conciernen a ese régimen en calidad y cantidad suficientes.

Si se hacen ejercicios estadísticos y de encuesta se demostraría que hasta ahora se carece de un régimen de propiedad adecuado; un crecido número de mexicanos no han arreglado sus escrituras de propiedad; la posesión de muchos de sus predios está en la indefinición; muchas personas no han emitido testamento alguno; los documentos y bienes que amparan con frecuencia son irregulares. Estos son algunos de los cotidianos pero lastimosos problemas de seguridad jurídica que padecen muchos de nuestros conciudadanos, que no tienen sus papeles en orden por ignorancia, descuido y muchas veces por falta de recursos económicos para pagar un notario o un corredor.

Ante esta situación, es imperativo renovar y actualizar las funciones que conciernen a la fe pública, abrir los cotos cerrados que se presentan tanto en la función notarial como en la correduría, permitiendo que haya suficientes prestadores de estos servicios, a menor costo y con procedimientos más ágiles en beneficio de todos.

El Senado debe situarse más allá de la polémica y de la iniciativa. La solución no consiste en inclinarse a favor de los notarios o los corredores públicos, respuesta simplista, sino en superar esta disputa gremial con una legislación inteligente y de avanzada. 


\section{ACCIONES A SEGUIR QUE SE SUGIEREN}

A nuestro juicio, el Senado no está en este momento en condiciones de pronunciarse sobre la iniciativa de que se trata antes de dictaminarla, se deben efectuar cuando menos las siguientes acciones:

a) Foros de consulta y reuniones de consenso que permitan expresar sus puntos de vista a los sectores involucrados, a los expertos, a las instituciones de educación superior y a la ciudadanía. El objetivo sería obtener puntos de consenso para una adecuada legislación.

b) Un estudio a fondo sobre el notariado y la correduría pública es indispensable para evaluar su actual régimen jurídico, los métodos de acceso, los costos por los servicios e incluso el mercado de trabajo de ambas funciones. El Senado a través de sus comisiones correspondientes y la Cámara de Diputados por medio del Centro de Investigaciones Legislativas pueden promover dicho estudio.

c) Se requiere también un estudio comparativo en el mundo ${ }^{6}$ acerca del notariado y la correduría, antes de cualquier decisión, siempre es muy útil conocer otras experiencias que pueden servirnos para mejorar nuestra legislación y proponer adecuadas reformas.

d) Una ley general sobre la fe pública puede expedirse, siempre y cuando la materia por reforma constitucional se haga concurrente, en la cual se establezca un régimen moderno y eficaz para la prestación del servicio de notarios, corredores y otros fedatarios. Esta ley deslindaría con precisión la naturaleza de la función notarial y de la correduría, así como resolvería los puntos de conflicto, con respeto obviamente del ejercicio de la autonomía local en la materia.

e) Los procedimientos de ingreso y los exámenes para ser notario público o corredor carecen actualmente de equilibrio y transparencia, debido a los intereses en juego. Así lo visualizaba, en un artículo sobre el tema, Niceto Alcalá-Zamora y Castillo, ${ }^{7}$ cuando decía que la asignación

6 A este respecto, son de obligada consultas las obras siguientes: Revista Internacional del Notariado, año XXIII, núm. 71; Revista de la Asociación de Escribanos del Uruguay, núms. 1 a 12, enero a diciembre de 1997, t. 83; Font-Boix, Vicente, "Acotaciones al tema del notariado latino en Inglaterra", Revista de Derecho Notarial, año XXIII, núm.74, marzo de 1979.

7 Alcalá-Zamora y Castillo, Niceto, “Oposiciones y colegiaciones en el notariado mexicano”, Revista de Derecho Notarial, México, núm. 74, año XXIII, marzo de 1979, pp. 11 y ss. 
de la fe pública se deje libremente al Ejecutivo (sea federal o local agregamos), se corre el grave riesgo de que a tal función sólo arriben los compinches y los paniaguados, en tanto que si se deja a las propias profesiones o colegios, el peligro estriba en que el espíritu de cuerpo y las relaciones personales inclinen la balanza.

f) Jurados autónomos, objetivos e imparciales son indispensables en los procedimientos de ingreso y en los exámenes de oposición, con participación obvia pero no determinante del gremio correspondiente y del propio poder público; la academia, el foro y la representación ciudadana deben también incluirse.

g) Debe contemplarse, finalmente, la participación de las universidades y las instituciones de educación superior, que en sus posgrados podrían establecer especializaciones en materia notarial, de correduría $\mathrm{y}$ registral que pudieran constituirse en requisito previo para el ejercicio de las referidas funciones. 